\title{
Development of Fixed Time Kinetic Spectrophotometric Method for Selective Determination of Metformin in Pharmaceutical Formulations
}

\author{
SHIVAJI R. LABHADE ${ }^{1 *}$, KAILAS R. LABHADE ${ }^{2}$ and VISHWAS B. GAIKWAD ${ }^{3}$ \\ ${ }^{1}$ Department of Chemistry, K. T. H. M. College, Gangapur Road, Shivajinagar, \\ Nashik- 422 002, India \\ ${ }^{2}$ Department of Chemistry, S.V.K.T. Arts, Science and Commerce College, Deolali Camp, \\ Nashik- 422 401, India \\ ${ }^{3}$ Director, BCUD, University of Pune, Ganeshkhind, Pune-411 007, Maharashtra State, India \\ srlabhade3571@rediffmail.com
}

Received 16 September 2014 / Accepted 25 September 2014

\begin{abstract}
A fixed time kinetic spectrophotometric method has been developed for the selective determination of metformin hydrochloride in bulk and in tablet formulation. This experiment indicates that at room temperature alkaline solution metformin is oxidized to $\beta$-diketone by the action of sodium hypochlorite, the product is subsequently reacts with sodium nitroprusside to give a green colored 1, 3 dinitrosyl- $N$ '-(iminomethyl)- $N, N$-dimethyl formamidine complex with maximum absorption at $685 \mathrm{~nm}$. In sodium hydroxide-boric acid buffer solution, this time dependent chromophoric reaction reaches to a state of maximum absorbance within 5 minutes. At a preselected time of 5 minutes (after initiation of reaction) readings of maximum absorbance were adopted for constructing the calibration curve. Beer's law is obeyed over the concentration range of 10-120 $\mu \mathrm{g} . \mathrm{mL}^{-1}$ with molar absorptivity and Sandell's sensitivity of $6.335 \times 10^{4} \mathrm{~L} . \mathrm{Mol}^{-1} \cdot \mathrm{cm}^{-1}$ and $0.0261 \mu \mathrm{g} \cdot \mathrm{mL}^{-1}$ respectively. The linear regression equation is $\mathrm{A}=0.004+0.003 \mathrm{C}\left(\mu \mathrm{g} . \mathrm{mL}^{-1}\right)$ with a regression coefficient $\left(r^{2}=0.999\right)$. The percent recovery of the method is $100.04 \%$ with average relative error $0.038 \%$ and average relative standard deviation (RSD) $0.319 \%$. The parameters with regard to determination of metformin by proposed method are optimized. The reaction mechanism and reaction stoichiometry is discussed. The proposed method was successfully applied for estimation of metformin in commercially available metformin tablets containing glibenclamide, glimepiride, glipizide and gliclazide. The average accuracy was found good, which was evaluated by comparison of the results obtained with those claimed by the manufacturer.
\end{abstract}

Keywords: Metformin Determination, Sodium Nitroprusside, Sodium Hypochlorite, Metformin Hydrochloride, Glibenclamide, Glimepiride, Glipizide, Gliclazide

\section{Introduction}

Metformin hydrochloride ( $\mathrm{MHCl})$ is an oral antihyperglycaemic agent used to lower blood glucose in patients suffering from diabetes of non-insulin dependent ${ }^{1}$. Chemically metformin is $\mathrm{N}, \mathrm{N}$-dimethylimidodicarbonimidic diamide hydrochloride ${ }^{2}$ with molecular weight $165.62 \mathrm{~g} / \mathrm{mol}$. 
<smiles>CNC(=N)NC(=N)N(C)C</smiles>

Figure 1. Chemical structure of $\mathrm{MHCl}$

Literature review indicates several methods for the determination of $\mathrm{MHCl}$ alone or in combination with various drugs in pharmaceutical preparations. $\mathrm{MHCl}$ has been determined by titration in an acetic acid medium with perchloric acid $^{3}$ using several indicators. Also, potentiometrically it was estimated in glacial acetic acid and mercury(II) acetate medium using perchloric acid $^{1}$ and PVC membrane sensors ${ }^{4-5}$. Fluorimetric determination of $\mathrm{MHCl}$ involved its reaction with chrysenequinone and 1-naphthol in alkaline medium ${ }^{5}$. Conductometric assay of $\mathrm{MHCl}$ was carried out with copper sulfate ${ }^{6}$, silver nitrate ${ }^{7}$ and sodium tetraphenylborate with cetylpyridinium bromide ${ }^{8}$. Various HPLC methods have been reported for determination of $\mathrm{MHCl}$ in human plasma $^{9-13}$ and in pharmaceutical preparations ${ }^{14-15}$. In addition, reversed-phase liquid chromatography ${ }^{16-18}$, liquid chromatography-mass spectrometry ${ }^{19}$, tandem mass spectrometry ${ }^{20-23}$, gas chromatography ${ }^{24}$, and capillary electrophoresis ${ }^{25-27}$ methods are found in the literature for determination $\mathrm{MHCl}$. Most of these methods are time consuming and required an expensive instrumentation.

Several spectrophotometric methods are reported for determination of $\mathrm{MHCl}$. These includes direct determination with multivariate calibration technique ${ }^{28}$, reaction of $\mathrm{MHCl}$ with cupric ion and cyclohexylamine in basic medium ${ }^{5}$, formation of oxidative coupling of the reaction product of $\mathrm{MHCl}$ with 1-naphthol ${ }^{29}$, oxidation of $\mathrm{MHCl}$ to yellow-colored chromophore $^{30}$, formation of charge transfer complex of $\mathrm{MHCl}$ with iodine in acetonitrile medium $^{31}$ as well as the first-derivative method ${ }^{32}$. Spectrophotometry is the most common and convenient analytical tool of analytical laboratories due to its inherent sensitivity and low costing. Up till now no kinetic spectrophotometric method has been reported for quantification of $\mathrm{MHCl}$ using sodium nitroprusside. This initiated our present study.

Sodium nitroprusside (SNP), $\mathrm{Na}_{2}\left[\mathrm{Fe}(\mathrm{CN})_{5} \mathrm{NO}\right]$ is a popular derivatization agent of analytically important for the detection and determination of wide variety nucleophilic moieties such as primary or secondary aliphatic amines, aldoximes, ketones, nitrites, phenols, pyrroles, quinones, thiols, thioureas and uracils ${ }^{33-34}$. Many spectrophotometric methods adapted SNP as an analytical reagent in their applications, including the assays of

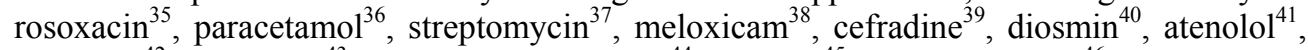
methanol $^{42}$, piroxicam ${ }^{43}$, sumatriptan succinate $^{44}$, ramipril $^{45}$ and thiosulphate ${ }^{46}$. Furthermore, the techniques like HPLC ${ }^{47}$ and flow injection analysis ${ }^{48}$ also adapted SNP as an analytical reagent in their applications. In addition, the coupling reaction of SNP with diazotized $p$-nitroaniline in basic solution also been used for spectrophotometric determination ${ }^{49}$ of SNP. Also, for detection of impurities with TLC, metformin also been identified by using the mixture of SNP and potassium ferrocyanide with $\mathrm{NaOH}$ solution ${ }^{50}$, but this test does not involved oxidation of metformin by $\mathrm{NaOCl}$.

Spectrophotometric methods of determinations of metformin ${ }^{29-30}$ and paracetamol ${ }^{51}$ have been utilized $\mathrm{NaOCl}$ as an oxidizing reagent for oxidation of the analytes. It has been reported that using $\mathrm{NaOCl}$ metformin is oxidized to its $\beta$-diketone, the product is subsequently react with SNP in basic solution due to nucleophilic reactivity of oxygen atoms of the $\beta$-diketone with electrophilic nitrosyl groups of two SNP molecules, to give a green colored 1, 3 dinitrosyl- $N$ '-(iminomethyl)- $N, N$-dimethyl formamidine complex. In $\mathrm{NaOH}$ this time dependent reaction is completed within 3 minutes and generated product undergoes 
degradation immediately after 3 minutes $^{52}$, therefore determination of metformin is not possible through measurement of a concrete absorbance value. It has been proved that, in $\mathrm{NaOH}-\mathrm{H}_{3} \mathrm{BO}_{3}$ buffer solution reaction of the oxidized product of $\mathrm{MHCl}$ with SNP reaches to a state of maximum absorbance within 5 minutes and remains in same state for about one minutes. The reaction allows sufficient time for absorbance measurement, therefore fixed time kinetic spectrophotometric method adopted for quantification of $\mathrm{MHCl}$ which is described in this manuscript.

\section{Experimental}

A Shimadzu Double beam UV-visible spectrophotometer (UV-1800) with software UVProbe 2.33 and $10 \mathrm{~mm}$ matched quartz silica cells was used for all spectral and absorbance measurements.

\section{Reagent and materials}

All the chemicals used were of analytical grade or pharmaceutical grade and used without further purification. Distilled water was used for diluting the standard, reagents and samples. All the prepared reagents were stored in the amber colored bottles and protected from direct sunlight.

Sodium nitroprusside (SNP) solution

A $1.0 \times 10^{-2} \mathrm{~mol} \mathrm{~L}^{-1}$ solution was prepared freshly by dissolving $1.490 \mathrm{~g}$ of $\mathrm{Na}_{2}\left[\mathrm{Fe}(\mathrm{CN})_{5} \mathrm{NO}\right] \cdot 2 \mathrm{H}_{2} \mathrm{O}$ in $500 \mathrm{~mL}$ of distilled water.

Sodium hypochlorite ( $\mathrm{NaOCl}$ ) solution

A $0.1 \%$ solution was prepared by diluting $12.5 \mathrm{~mL}$ of $4 \%$ sodium hypochlorite to $500 \mathrm{~mL}$ with distilled water.

\section{Sodium hydroxide-Boric acid (Borax buffer) solution}

Prepared by dissolving $3.100 \mathrm{~g}$ of $\mathrm{H}_{3} \mathrm{BO}_{3}$ in $500 \mathrm{~mL}$ of $1.0 \mathrm{~mol} \mathrm{~L}^{-1}$ of aqueous $\mathrm{NaOH}$ solution.

\section{Standard metformin hydrochloride (MHCl) solution}

A stock solution of $1.0 \times 10^{-3} \mathrm{~mol} \mathrm{~L}^{-1}$ of $\mathrm{MHCl}$ was prepared by dissolving $82.8 \mathrm{mg}$ of pharmaceutical grade $\mathrm{MHCl}\left(\mathrm{C}_{4} \mathrm{H}_{11} \mathrm{~N}_{5} \mathrm{HCl}, 165.62 \mathrm{~g} \mathrm{~mol}^{-1}\right)$ in $500 \mathrm{~mL}$ of distilled water. Working solutions of 16.56 and $20.0 \mu \mathrm{g} \mathrm{mL}^{-1}$ of $\mathrm{MHCl}$ were prepared by diluting $10.0 \mathrm{~mL}$ and $12.1 \mathrm{~mL}$ of this solution respectively to $100 \mathrm{~mL}$ with distilled water.

\section{Dosage forms}

The metformin containing tablets, Metfor, Glycomet, Diabetrol, Reclimate, Gemer 1 and Actizide- $M$ were purchased from commercial sources and subjected to analysis.

\section{Recommended procedures}

\section{Caution}

Potentially hazardous volatile gases may possibly be evolved during the experimentation.

\section{Procedure for determination of metformin in pure drug}

Aliquots of $6.0 \mathrm{~mL}$ of standard solution containing 10.0-120.0 $\mu \mathrm{g}$ of $\mathrm{MHCl}$ were transferred to $50 \mathrm{~mL}$ beakers containing $1.0 \mathrm{~mL}$ of $\mathrm{NaOH}-\mathrm{H}_{3} \mathrm{BO}_{3}$ buffer solution. For measurement of absorbance of the first solution, $1.0 \mathrm{~mL}$ of $0.1 \% \mathrm{NaOCl}$ solution was added and after thoroughly 
mixing of reaction mixture, immediately $2.0 \mathrm{~mL}$ of $1.0 \times 10^{-2} \mathrm{~mol} \mathrm{~L}^{-1}$ of SNP solution was added. At the end of addition of last SNP reagent, time measurement was started by using stop-watch. Meanwhile reaction mixture was again systematically mixed and immediately place in the optical beam of the spectrophotometer using $10 \mathrm{~mm}$ quartz cell, against distilled water blank (since the composition of the reagent blank solution changes with the time). After 60 seconds the absorbance of reaction mixture was monitored at $685 \mathrm{~nm}$ via putting spectrophotometer in the kinetic mode and absorbance reading at 300 seconds (viz. at 5 minutes after initiation of reaction) was recorded. During experimentation, each solution was treated independently in absence of direct sunlight for a fixed time span and absorbance was recorded. The calibration curve was constructed by plotting the absorbance values (measured at 300 seconds) against the concentration of the metformin. The amount of the metformin in the sample was computed either from calibration curve or regression equation.

\section{Procedure for determination of metformin in tablet formulations}

A single tablet of $\mathrm{MHCl}$ was weighed and finely powdered. An accurate weight of $20 \mathrm{mg}$ of powdered $\mathrm{MHCl}$ was transferred to $100 \mathrm{ml}$ distilled water. The solution was stirred for 3-4 minutes and filtered through a Whatman No 42 filter paper. The filtrate contains $\mathrm{MHCl}$, while other drug ingredients (glibenclamide, glimepiride, glipizide and gliclazide) and excipients present in tablet remains insoluble. A $10.0 \mathrm{~mL}$ of this filtrate was further diluted to $100 \mathrm{~mL}$ with distilled water and a working sample was prepared. Different aliquots of known volume of working sample were analyzed by the recommended fixed-time spectrophotometric method. The amount of the metformin in tablet was computed from calibration curve method.

\section{Results and Discussion}

The time dependency of a chromogenic reaction, its short life time becomes hurdle in determining a concrete absorbance value. Kinetic spectrophotometric method is an alternative approach for quantification of such compounds which increases the absorbance within time of reaction. Reaction of the oxidized product of metformin ( $\beta$-diketone) with SNP fulfills these limitations. Thus, it could help in establishing suitable method for determination of $\mathrm{MHCl}$ in pure drug and in certain pharmaceutical formulations.

\section{Absorption spectrum}

In present investigation, green colored complex of 1, 3 dinitrosyl- $N^{\prime}$-(iminomethyl)- $N, N$ dimethyl formamidine is formed in $\mathrm{NaOH}-\mathrm{H}_{3} \mathrm{BO}_{3}$ buffer solution by the reaction of $\mathrm{MHCl}$ with $\mathrm{NaOCl}$ and SNP. It can be seen that (Figure 2), the maximum absorption wavelength of the green colored product is at $685 \mathrm{~nm}$. Except the reaction product all the reagents as well as reagent blank solution are transparent at $685 \mathrm{~nm}$. All the absorption spectra of reaction product (5-10) were obtained 5 minutes after the initiation of reaction. Maximum absorbance value obtained for corresponding concentration of metformin is given in the bracket.

\section{Mechanism of the Chromogenic Reaction}

$\mathrm{MHCl}$ in alkaline medium (buffered with $\mathrm{NaOH}-\mathrm{H}_{3} \mathrm{BO}_{3}$ ) oxidized to $\beta$-diketone by the action of $\mathrm{NaOCl}$, the product thus formed is progressively reacts with SNP to give a green colored 1, 3 dinitrosyl- $N$ '-(iminomethyl)- $N$, $N$-dimethyl formamidine complex (Figure 3). SNP has ability to react with many nucleophilic agents in basic solution and form the colored derivative because of electrophilic reactivity of its nitrosyl group ${ }^{33-34}$. 


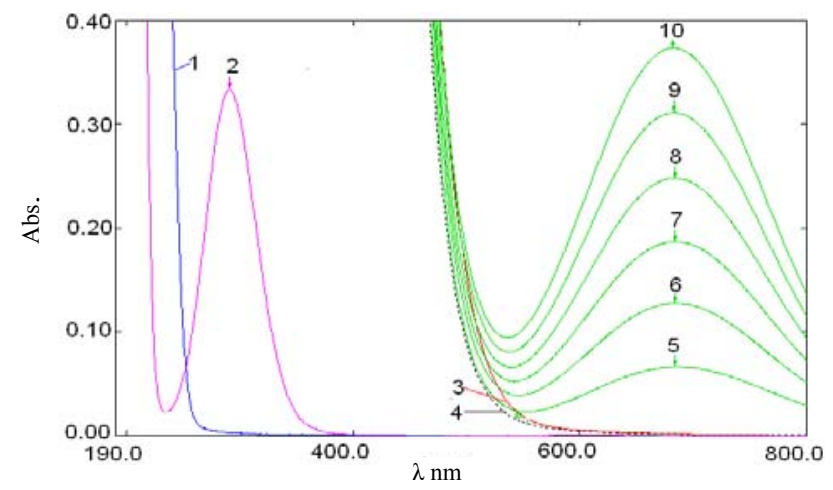

Figure 2. Absorption spectrum (obtained against distilled water) at $10 \mathrm{~mL}$ dilution with 1.0 $\mathrm{mL}$ buffer solution of $5.0 \times 10^{-4} \mathrm{M}$ of $\mathrm{MHCl}$ solution, (1) $1.0 \mathrm{~mL}$ of $0.1 \% \mathrm{NaOCl}$ solution, (2) $2.0 \mathrm{~mL}$ of $1.0 \times 10^{-2} \mathrm{~mol} \mathrm{~L}^{-1}$ of SNP solution, (3) reagent blank solution and (4) the reaction product with $1.0 \times 10^{-4} \mathrm{M}(5, \mathrm{~A}=0.067), 2.0 \times 10^{-4} \mathrm{M}(6, \mathrm{~A}=0.129), 3.0 \times 10^{-4} \mathrm{M}(7, \mathrm{~A}=0.188)$, $4.0 \times 10^{-4} \mathrm{M}(8, \mathrm{~A}=0.242), 5.0 \times 10^{-4} \mathrm{M}(9, \mathrm{~A}=0.312), 6.0 \times 10^{-4} \mathrm{M}(10, \mathrm{~A}=0.378)$ of $\mathrm{MHCl}$<smiles>CN(C)C(=N)NC(=N)N</smiles><smiles>CCCONC(=O)NC(=O)N(C)C</smiles>

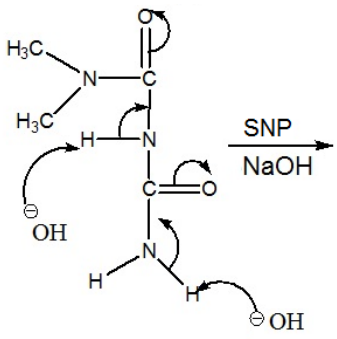

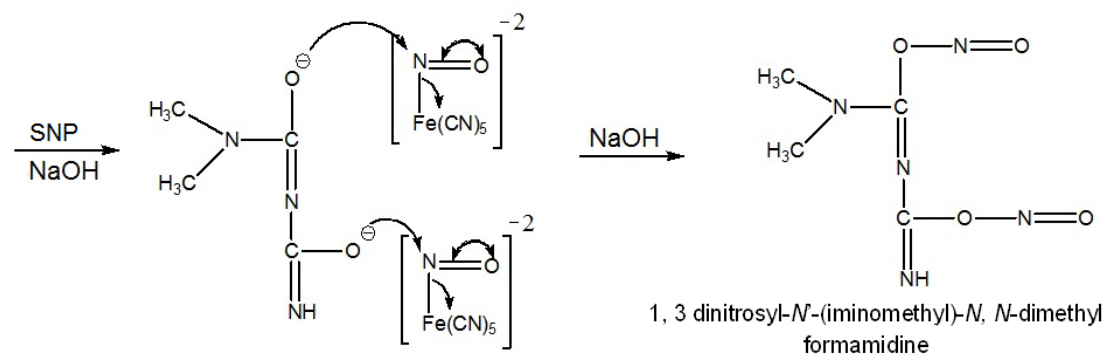

Figure 3. Mechanism of the chromogenic reaction

As a result the oxygen atoms of $\beta$-diketone of $\mathrm{MHCl}$ trends to attack electron deficiency center in nitrosyl groups of two SNP molecules to give green color product. Similar reaction reported for determination of paracetamol ${ }^{36}$ illustrates that, paracetamol molecule is linked to nitrosyl group through phenolic oxygen and gives green colored compound with absorption maxima at $700 \mathrm{~nm}$. Development of green color to these products is due to conjugation of double bonds by means of electron donor oxygen atoms and electron acceptor nitrosyl groups. The $\beta$-diketone of $\mathrm{MHCl}$ shows inertness towards both potassium ferrocyanide and potassium ferricyanide. Consequently the cyanide ligand of the nitroprusside anion does not involve in the chromogenic reaction. Furthermore, it was observed that the addition of potassium ferricyanide with alkaline sodium nitroprusside does 
not develop the green color with metformin in $\mathrm{NaOCl}$ solution, but the addition of potassium ferrocyanide does not affect color development. Chromogenic reaction (Figure 3) occurs only in basic medium $(\mathrm{pH}=12.8)$ because of formation of the $\left[\mathrm{Fe}(\mathrm{CN})_{5} \mathrm{NO}(\mathrm{OH})\right]^{3-}$; active component of the sodium nitroprusside after its reaction with $\mathrm{NaOH}^{42,53}$. In addition, the reaction was initiated only with the addition of sodium hypochlorite oxidizing reagent. Time and sequence of addition of the reagents as well as amount of reagent affects the rate of reaction.

\section{Linearity in measurement of absorbance}

Initially, growth and stability of the colored product was studied by measuring increase in absorbance at $685 \mathrm{~nm}$ as a function of time for the reaction of varying concentration of metformin. Different standard solutions (at $10 \mathrm{ml}$ dilution) of metformin having concentration in the range $10-120 \mu \mathrm{g}$ were prepared using $1.0 \mathrm{~mL}$ buffer, $1.0 \mathrm{~mL}$ of $0.1 \% \mathrm{NaOCl}$ and $2.0 \mathrm{~mL}$ of $1.0 \times 10^{-2} \mathrm{~mol} \mathrm{~L}^{-1}$ of SNP respectively. Absorbance of the reaction was monitored (using kinetic mode of spectrophotometer) 60 seconds after the addition of final reagent SNP.

The absorbance-time curve (Figure 4) interprets that, in $\mathrm{NaOH}-\mathrm{H}_{3} \mathrm{BO}_{3}$ buffer absorbance of the reaction product increases slowly to maximum up to 300 seconds and after 360 seconds it starts declining. Furthermore, absorbance of the green colored product when measured at a 300 or 360 seconds, (for maximum molar absorptivity) was observed to be increasing proportionally to the concentration of metformin (Figure 5). Consequently fixed time kinetic method is found to be suitable for determination of metformin.

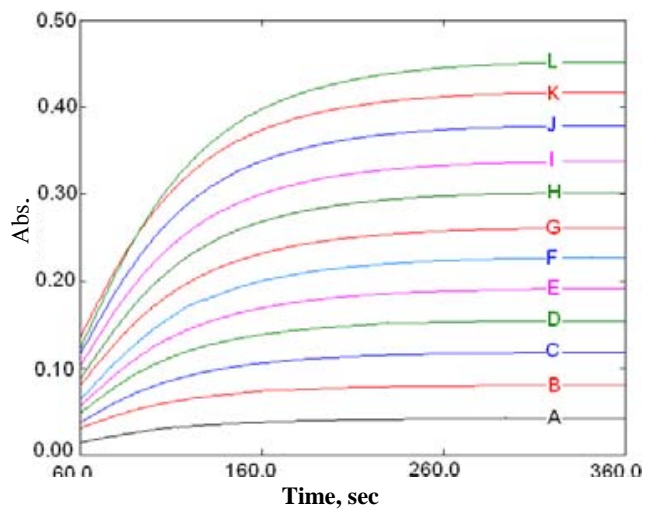

Figure 4. Absorbance-time curves (A to $\mathrm{L}$ ) for reaction of metformin with varied concentration $(10-120 \mu \mathrm{g})$

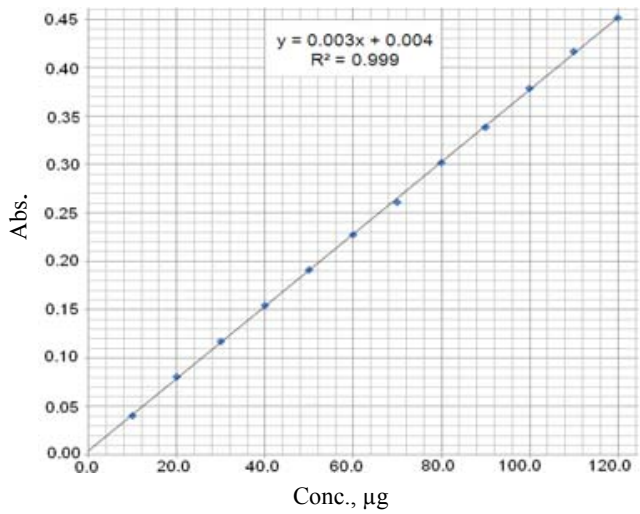

Figure 5. The calibration graph of absorbance (measured at $300 \mathrm{sec}$.) against the concentration of metformin in the range $10-120 \mu \mathrm{g}$

\section{Reaction stoichiometry}

Stoichiometric ratio for the reaction between $\beta$-diketone of the $\mathrm{MHCl}$ with SNP in $\mathrm{NaOH}-$ $\mathrm{H}_{3} \mathrm{BO}_{3}$ buffer solution was studied by the Job's method of continuous variation ${ }^{54}$ and by varying concentration of $\mathrm{MHCl}$ and SNP. For Job's method, standard working solutions of $0.5 \times 10^{-3} \mathrm{M}$ of $\mathrm{MHCl}$ and $1.0 \times 10^{-3} \mathrm{M}$ SNP were used. Concentration ratio of MHCl: SNP was maintained as 1:2 for a series of $12 \mathrm{ml}$ standard solutions of $\mathrm{MHCl}$ and SNP with different complementary proportions $(0: 10,1: 9, \ldots, 9: 1,10: 0)$ were prepared with $1.0 \mathrm{~mL}$ of $\mathrm{NaOH}-\mathrm{H}_{3} \mathrm{BO}_{3}$ buffer and $1.0 \mathrm{~mL}$ of $0.1 \% \mathrm{NaOCl}$ solutions. After measurement of absorbance, stoichiometry for the reaction of $\beta$-diketone of the $\mathrm{MHCl}$ and SNP reagent was observed to be $1: 2$ and 1.5:2. 
In the same way concentration variation method was used with variation in the volume of $\mathrm{MHCl}\left(\right.$ of $0.5 \times 10^{-3} \mathrm{M}$ ) and SNP (of $0.5 \times 10^{-3} \mathrm{M}$ ). At the beginning volume of SNP was kept constant $(10.0 \mathrm{~mL})$ and by changing the volume $(1.0-10.0 \mathrm{~mL})$ of metformin. Similarly, by keeping the volume of $\mathrm{MHCl}$ constant $(3.0 \mathrm{~mL})$ and changing the volume $(1.0-10.0 \mathrm{~mL})$ of SNP, absorbance of all the solutions was measured according to procedure. In both of these later cases, the absorption-time curves illustrate linear increase in absorbance till the concentration of metformin to SNP reaches in the ratio 1:2. From the stoichiometric study, it is concluded that in limited concentration of SNP, maximum molecules of $\beta$-diketone react with SNP through single oxygen atom and in excess concentration of SNP both oxygen of the $\beta$-diketone react with SNP. Other than two oxygen atom no active site in the $\beta$-diketone molecule is seen which can reacts with third nitrosyl group of SNP. Hence, it seems reasonable that in excess concentration of SNP, the reaction mechanism reported in Figure 3 is correct. The higher concentration of SNP is recommended for determination of metformin by proposed method since it helps to maintain reaction stoichiometry in 1:2 ratio with greater value of molar absorptivity.

\section{Optimization of reaction conditions}

The optimum conditions for the development of method were established by varying the parameters one at a time and keeping the others fixed and observing the effect produced on the absorbance-time curves of the green colored product.

\section{Effect of SNP concentration}

Sodium nitroprusside is functions as chromogenic reagent. Its concentration directly affects the absorbance of the reaction medium. The effect of concentration of SNP on the rate of the reaction was studied by keeping the concentration ( 60 or $20 \mu \mathrm{g})$ of metformin constant and altering the concentration of SNP $\left(1.0-5.0 \mathrm{~mL}\right.$ of $\left.1.0 \times 10^{-2} \mathrm{M}\right)$. It was observed that, absorbance of reaction mixture increases with increasing volume of SNP from 1.0 to $3.0 \mathrm{~mL}$. It is interesting to know that, volume of SNP greater than $3.0 \mathrm{~mL}$ does not affect the absorbance values significantly. For determination of metformin upto $120 \mu \mathrm{g}, 2.0 \mathrm{~mL}$ volume of $1.0 \times 10^{-2} \mathrm{M} \mathrm{SNP}$ was found adequate which is approximately 100 times greater than analyte concentration.

\section{Effect of NaOCl concentration}

Sodium hypochlorite acts as oxidizing reagent because of its ability of releasing free chlorine in aqueous medium. This free chlorine has absorbance quenching ability. The concentration of $\mathrm{NaOCl}$ greatly affects the reaction rate (in terms of oxidation of metformin) and absorbance (in terms of color bleaching property) of the reaction product. Free chlorine released by $1.0 \mathrm{~mL}$ of $0.1 \% \mathrm{NaOCl}$ was found adequate for oxidation of metformin up to $120 \mu \mathrm{g}$. Moreover, the reaction $\mathrm{MHCl}$ with SNP is initiated only with the addition of $\mathrm{NaOCl}$.

\section{Effect of buffer concentration}

SNP acts as electrophilic agent in basic medium due to formation of $\left[\mathrm{Fe}(\mathrm{CN})_{5} \mathrm{NO}(\mathrm{OH})\right]^{3-}$ active component after its reaction with $\mathrm{NaOH}^{42,53}$. The reaction of $\beta$-diketone of $\mathrm{MHCl}$ and SNP also occurs in strong basic medium containing $\mathrm{NaOH}$. The rate of formation and degradation of the green color product was observed to be faster, when reaction was carried with only $\mathrm{NaOH}$ solution ${ }^{52}$. For controlling the $\mathrm{pH}$ of the reaction medium when boric acid $\left(\mathrm{H}_{3} \mathrm{BO}_{3}\right)$ was added along with $\mathrm{NaOH}$, the rate of formation and degradation of the product was observed to be slower. In $\mathrm{NaOH}-\mathrm{H}_{3} \mathrm{BO}_{3}$ buffer solution $(\mathrm{pH}=12.8)$ reaction reaches to a 
state of maximum absorbance within 5 minutes and the absorbance remains constant for a time span of 1 minute, sufficient for absorbance measurement. The buffer solution greater than $1.0 \mathrm{~mL}$ does not show much improvement in the absorbance readings.

\section{Sequence of addition reagent}

The rate of the chromogenic reaction was observed to be varied with the sequence of addition of reagents. Initially, $6.0 \mathrm{~mL}$ aliquot of metformin solution was placed in a $1.0 \mathrm{~mL}$ of buffer solution, Just before absorbance measurement $1.0 \mathrm{~mL}$ of $0.1 \% \mathrm{NaOCl}$ and $2.0 \mathrm{~mL}$ of $0.01 \mathrm{M} \mathrm{SNP}$ was added. Absorbance of the reaction mixture was measured according to the procedure described earlier. The parameters for selective and sensitive determination of $\mathrm{MHCl}$ are accordance with in Table 1 .

Table 1. Summary for the optimization of variables affecting the reaction of $\mathrm{MHCl}$ with SNP reagent employed in the development of the proposed spectrophotometric method

\begin{tabular}{lll}
\hline \multicolumn{1}{c}{ Variable } & \multicolumn{1}{c}{ Studied Range } & \multicolumn{1}{c}{ Optimum } \\
\hline Conc. range of MHCl & $10.0-120.0 \mu \mathrm{g}$ & $10.0-120.0 \mu \mathrm{g}$ \\
Volume of $0.01 \mathrm{M} \mathrm{SNP}$ & $1.0-5.0 \mathrm{~mL}$ & $2.0 \mathrm{~mL}$ \\
Volume of $0.1 \% \mathrm{NaOCl}$ & $0.5-3.0 \mathrm{~mL}$ & $1.0 \mathrm{~mL}$ \\
Volume of buffer solution & $0.5-4.0 \mathrm{~mL}$ & $1.0 \mathrm{~mL}$ \\
pH range & 12.8 & 12.8 \\
Temperature & $25^{\circ} \mathrm{C}$ (Room temp.) & $25^{\circ} \mathrm{C}$ \\
\hline
\end{tabular}

Sensitivity of the method

Sensitivity of the spectrophotometric method is often described in terms of the molar absorptivity $(\varepsilon)$ and Sandell's sensitivity of the color product formed. With variable concentration of metformin (Figure 2), the molar absorptivity value for green colored product at $685 \mathrm{~nm}$ was found $6.335 \times 10^{4} \mathrm{~L}$. $\mathrm{Mol}^{-1} \cdot \mathrm{cm}^{-1}$. Sandell's sensitivity ${ }^{54}$ of the green color product was observed $0.0261 \mu \mathrm{g} . \mathrm{mL}^{-1}$. Higher value of molar absorptivity and lower value of Sandell's sensitivity indicates suitability of the current method in determination of metformin.

\section{Quantification of metformin}

A linear correlation was found between absorbance and concentration of metformin in the range $10-120 \mu \mathrm{g}$ (Figure 4 and 5). Beer's law calibration curve was used for calculation of concentration of metformin. Analytical and optical parameters reported in Table 2 predict suitability of the method. In order to determine the accuracy and precision of the method, solutions containing four different concentration of metformin were prepared and analyzed five times. The results reported in Table 3 indicate that proposed method has good accuracy and good precision.

Table 2. Analytical and optical parameters for the performance of the proposed spectrophotometric method for determination of metformin

\begin{tabular}{ll}
\hline \multicolumn{1}{c}{ Statistical Parameter Tested } & \multicolumn{1}{c}{ Parameter Values } \\
\hline Measurement wavelength $(\lambda-\max )$ & $685 \mathrm{~nm}$ \\
Stoichiometric ratio MHCl: SNP (in excess) & $1: 2$ \\
Beer's law limit & $10.0-120.0 \mu \mathrm{g}$ \\
Preselected time of measurement & 300 or $360 \mathrm{Sec}$. \\
Molar Absorptivity & $6.335 \times 10^{4} \mathrm{~L} . \mathrm{Mol}^{-1} . \mathrm{cm}^{-1}$ \\
Sandell's Sensitivity (0.001 Abs. unit) & $0.0261 \mu \mathrm{g} \mathrm{mL}{ }^{-1}$ \\
Regression equation & $\mathrm{A}=4.0 \times 10^{-3}+3.0 \times 10^{-3} \mathrm{C}$ \\
Regression coefficient $\left(\mathrm{r}^{2}\right)$ & 0.999 \\
\hline
\end{tabular}


Table 3. Evaluation of accuracy and precision in determination of metformin by the proposed method

\begin{tabular}{|c|c|c|c|c|c|c|c|}
\hline \multirow{2}{*}{\multicolumn{2}{|c|}{$\begin{array}{c}\mathrm{MHCl} \\
\mu \mathrm{g} / 10 \mathrm{~mL}\end{array}$}} & \multicolumn{3}{|c|}{ Accuracy } & \multicolumn{3}{|c|}{ Precision } \\
\hline & & \multirow{2}{*}{$\begin{array}{c}\text { Recovery, } \\
\%\end{array}$} & \multirow{2}{*}{$\begin{array}{l}\text { Absolute } \\
\text { Error }\end{array}$} & \multirow{2}{*}{$\begin{array}{l}\text { Relative } \\
\text { Error, \% }\end{array}$} & \multirow{2}{*}{$\begin{array}{c}\text { Average } \\
\text { Deviation }\end{array}$} & \multirow{2}{*}{$\begin{array}{l}\text { Relative Std. } \\
\text { Deviation, \% }\end{array}$} & \multirow{2}{*}{$\begin{array}{c}\text { Standard } \\
\text { Deviation }\end{array}$} \\
\hline Taken & Found* & & & & & & \\
\hline 20.0 & 19.9 & 99.50 & -0.10 & -0.50 & 0.10 & 0.503 & 0.150 \\
\hline 40.0 & 40.2 & 100.50 & 0.20 & 0.50 & 0.12 & 0.298 & 0.158 \\
\hline 60.0 & 60.1 & 100.17 & 0.10 & 0.17 & 0.20 & 0.333 & 0.255 \\
\hline 80.0 & 79.7 & 99.63 & -0.30 & -0.38 & 0.24 & 0.301 & 0.291 \\
\hline \multirow[t]{2}{*}{100.0} & 100.4 & 100.40 & 0.40 & 0.40 & 0.16 & 0.159 & 0.200 \\
\hline & Average: & 100.04 & -- & 0.038 & -- & 0.319 & 0.211 \\
\hline
\end{tabular}

*Average of five determinations

\section{Analytical application}

The validity of the proposed procedure was tested through determination of the metformin drug in its dosage forms. Following dosage forms were subjected for determination of metformin: Metfor (500 mg MHCl), Glycomet (500 mg MHCl), Reclimate (500 mg MHCl $+80 \mathrm{mg}$ gliclazide), Diabetrol (500 $\mathrm{mg} \mathrm{MHCl}+5 \mathrm{mg}$ glibenclamide), Gemer 1 (500 mg $\mathrm{MHCl}+1 \mathrm{mg}$ glimepiride) and Actizide-M (500 $\mathrm{mg} \mathrm{MHCl}+5 \mathrm{mg}$ glipizide). The active drugs such as gliclazide, glibenclamide, glimepiride and glipizide present in dosages forms (are water insoluble) in combination with metformin does not react ${ }^{52}$ with SNP in presence of $\mathrm{NaOCl}$, therefore calibration technique was adopted. The results obtained are given in Table 4.

Table 4. Statistical analysis of results obtained by the proposed method for the determination of metformin its tablet formulation

\begin{tabular}{lcccccc}
\hline Tablet & $\begin{array}{c}\text { MHCl found } \\
\text { in working } \\
\text { sample*, } \mu \mathrm{g}\end{array}$ & $\begin{array}{c}\text { MHCl found } \\
\text { in tablet* mg }\end{array}$ & $\begin{array}{c}\text { Recovery, } \\
\%\end{array}$ & $\begin{array}{c}\text { Absolute } \\
\text { Error }\end{array}$ & $\begin{array}{c}\text { Relative } \\
\text { Error, \% }\end{array}$ & $\begin{array}{c}\text { Relative Std. } \\
\text { Deviation \% }\end{array}$ \\
\hline Metfor & 20.09 & 502.25 & 100.45 & -2.25 & +0.45 & 0.15 \\
Glycomet & 19.90 & 497.50 & 99.50 & -2.50 & -0.50 & 0.21 \\
Reclimate & 19.98 & 499.50 & 99.90 & -0.50 & -0.10 & 0.30 \\
Diabetrol & 20.13 & 503.25 & 100.65 & +3.25 & +0.65 & 0.25 \\
Gemer-1 & 19.95 & 498.75 & 99.75 & -1.25 & -0.25 & 0.33 \\
Actizide-M & 20.06 & 501.50 & 100.30 & +1.50 & +0.30 & 0.39 \\
\hline
\end{tabular}

\section{Conclusion}

*Average of four determinations

The results demonstrate the successful use of $\mathrm{NaOCl}$ and SNP in the development of a fixed time kinetic spectrophotometric method for selective determination of metformin at room temperature. The proposed method is characterized by its sensitivity, which permits the determination in visible region of a metformin in the large linear range of concentration, its simplicity in procedure and reliability in results. All analytical reagent used in this experiment are inexpensive and available in all analytical laboratory. The other active drug ingredients (glibenclamide, glimepiride, glipizide and gliclazide) and excipients present along with metformin in dosage forms did not interfere. The proposed method can be applied in quality control laboratories for the routine analysis of metformin in pure drug and tablet formulations. 


\section{Acknowledgement}

Authors are grateful to the Managing Committee of MVP Samaj, Nashik for providing the necessary infrastructure and instrumentations. Authors thank to the UGC, New Delhi and BCUD University of Pune, Pune for providing the sizable funds under the minor research projects.

This research article is dedicated to late Malogirao Sadashivrao Mogal (Malogikaka), the former Sarchitanis of MVP Samaj, who made major contribution to the society through social and educational development in Nashik District.

\section{References}

1. British Pharmacopoeia. Vol II, Cambridge University Press, Cambridge, 1988.

2. Bailey C J, Turner R C and Metformin N, Engl J Med., 1996, 334(9), 574-579; DOI:10.1056/NEJM199602293340906

3. Calatayud J M, Marti M C P and Falco P C, Analyst, 1985, 110, 981-984; DOI:10.1039/AN9851000981

4. Rizk M S, Electroanalysis, 1995, 7(7), 687-691; DOI:10.1002/elan.1140070717

5. Hassan S S M, Mahmoud W H, Elmosallamy M A and Othman A H, Anal Chim Acta, 1999, 378, 299-311; DOI:10.1016/S0003-2670(98)00500-5

6. Calatayud J M, Falco P C and Marti M C P, Anal Lett., 1985, 18(11), 1381-1390; DOI:10.1080/00032718508066218

7. Sartol E R, Suarez W T and Fatibello-Filho O, Quim Nova, 2009, 32(7), 1947-1950.

8. Abou-Dan M, Shour S A and Abou-Dan H, Asian J Chem., 2001, 13, 1-7.

9. Zarghi A, Foroutan S M, Shafaati A and Khoddam A, J Pharm Biomed Anal., 2003, 31(1), 197-200; DOI:10.1016/S0731-7085(02)00608-8

10. Zhang M, Moore G A, Lever M, Gardiner S J, Kirkpatrick C M and Begg E J, $J$ Chromatography B, 2002, 766(1), 175-179; DOI:10.1016/S0378-4347(01)00430-3

11. Yuen K H and Peh K K, J Chromatogr B Biomed Sci Appl., 1998, 710(1-2), 243-246; DOI:10.1016/S0378-4347(98)00117-0

12. Vesterqvist O, Nabbie F and Swanson B, J Chromatography B, 1998, 716(1-2), 299-304; DOI:10.1016/S0378-4347(98)00305-3

13. Tache F, David V, Farca A and Medvedovici A, Microchemical J, 2001, 68(1), 13-19; DOI:10.1016/S0026-265X(00)00170-3

14. Al-Rimawi F, Talanta, 2009, 79, 1368-1371; DOI:10.1016/j.talanta.2009.06.004

15. Onal Armagan, Eur J Med Chem., 2009, 44(12), 4998-5005; DOI:10.1016/j.ejmech.2009.09.003

16. Arayne M S, Sultana N and Zuberi M H, Pak J Pharm Sci., 2006, 19(3), 231-235.

17. Khanolkar D H and Shinde V M, Indian Drugs, 1999, 36(12), 739-742.

18. Kolte B L, Raut B B, Deo A A, Bagool M A and Shinde D B, J Chromatogr Sci., 2004, 42(2), 70-73; DOI:10.1093/chromsci/42.2.70

19. Cristina G, Florin A, Victor D and Andrei M. J Chromatogr B, 2007, 854(1-2), 211-218; DOI:10.1016/j.jchromb.2007.04.032

20. Marques M A S, Soares A S, Pinto O W, Barroso P T W, Pinto D P, Filho M F and Barroso E W, J Chromatogr B, 2007, 852(1-2), 308-316;

DOI:10.1016/j.jchromb.2007.01.030

21. Mistri H N, Jangid A G, Shrivastav P S, J Pharma Biomed Anal, 2007, 45(1), 97-106; DOI:10.1016/j.jpba.2007.06.003

22. Swales J G, Gallagher R T, Denn M and Peter R M, J Pharma Biomed Anal, 2011, 55(3), 544-551; DOI:10.1016/j.jpba.2011.02.030 
23. Chen X, Gu Q, Qiu F and Zhong D, J Chromatogr B, 2004, 802(2), 377-381; DOI:10.1016/j.jchromb.2003.12.017

24. Brohon J and Noel M, J Chromatography B: Biomed Sci Appl., 1978, 146(1), 148-151; DOI:10.1016/S0378-4347(00)81300-6

25. Hamdan I I, Bani Jaber A K and Abushoffa A M, J Pharma Biomedi Anal, 2010, 53(5), 1254-1257; DOI:10.1016/j.jpba.2010.03.017

26. Jing-Zheng Song, Hai-Feng Chen, Song-Jiu Tian and Zeng-Pei Sun, J Chromatogr B, 1998, 708(1-2), 277-283; DOI:10.1016/S0378-4347(97)00635-X

27. Yardimci C and Ozaltin N, Anal Chim Acta, 2005, 549(1-2), 88-95; DOI:10.1016/j.aca.2005.06.014

28. Arayne M S, Sultana N, Zuberi M H and Siddiqui F A, Indian J Pharm Sci., 2009, 71(3), 331-335; DOI:10.4103/0250-474X.56022

29. Ahmad N R and Omar F K. Iraqi National J Chem., 2012, 46, 161-170

30. Ahmad N.R, Iraq J Pharm, 2012, 12(1), 75-86

31. Ashour S and Kabbani R, Anal Lett., 2003, 36(2), 361-370; DOI:10.1081/AL120017696

32. Thomas A B and Patil S D, Der Pharma Chemica, 2011, 3(3), 271-276.

33. Rucki R, In: K. Florey (Ed.), Analytical Profile of Drug Substances, Vol. 6, Academic Press, New York. 1977; 488-513.

34. Leeuwenkamp O R, Van Benneekom W P and Bult A, in: Florey K (Ed.), Analytical Profile of Drug Substances, vol. 15, Academic Press, New York, 1986, 782-789.

35. Askal H F, Refaat I H, Darwish I A and Marzouq M A, Spectrochimica Acta Part A, 2008, 69(4), 1287-1291; DOI:10.1016/j.saa.2007.07.031

36. Yanyan Zhan, Yan Zhang, Quanmin Li and Xinzhen Du, J Anal Chem., 2011, 66(2), 215-220; DOI:10.1134/S1061934811020171

37. Quan-min Li and Lin-xiao Gao, Anal Lett., 2008, 41(14), 2595-2607;

DOI:10.1080/00032710802363354

38. Gurupadayya B M, Trinath M N and Shilpa K, Indian J Chem Technol., 2013, 20, 111-115.

39. Hua Zhang, Ling Li Wu, Quan Min Li and Xin Zhen Du, Chine Chem Lett., 2008, 19, 1470-1474; DOI:10.1016/j.cclet.2008.09.014

40. Zenovia M and Hassan Y Aboul Enein, Instru Sci Technol., 2011, 39(2), 135-148; DOI:10.1080/10739149.2010.545851

41. Bhashir N, Shah S W H, Bangesh M and Riazullah, J Sci Indu Res., 2011, 70, 51-54.

42. Yan-Yan Zhan, Yan Zhang, Quan-Min Li and Xin-Zhen Du, J Chinese Chem Soc., 2010, 57(2), 230-235; DOI:10.1002/jccs.201000035

43. Rele R V, Sawant S A and Warkar C B, Int J Chem Tech Res., 2010, 2(4), 2173-2176.

44. Kalyanaramu B and Raghubabu K, Der Pharma Chemica, 2011, 3(1), 223-228.

45. Kalyanaramu B, Raghubabu K and Vamsikumar Y, J Chem Pharm Res., 2011, 3(2), 863-869.

46. Sharma R, Rathore S S, Sharma P and Sharma A, J Chem Pharmace Res., 2009, 1(1), 321-328.

47. El-Walily A F, Abdine H H, Razak O A and Zamel S, J Pharm Biomed Anal., 2000, 22, 887-897.

48. Shah J, Jan M R and Rehman F, J Chil Chem Soc., 2008, 53(3), 1605-1608.

49. Rahawi K Y, Batool B Ibraheem and Hayfa M Jassim, Raf J Sci., 2011, 22(3), 119-128.

50. European Pharmacopoeia 5.0, Monographs M, 2003-2004 and European Pharmacopoeia 7.0, Monographs M, 2458-2459. 
51. Vilchez J L, Blanc R, Avidad R and Navalon A, J Pharma Biomed Anal., 1995, 13(9), 1119-1125; DOI:10.1016/0731-7085(95)01537-U

52. Labhade S R, Labhade K R and Gaikwad V B, Chem Sci Trans., 2014, 3(4), $1254-$ 1263, DOI:10.7598/cst2014.914 in press.

53. Katz N E, Blesa M A, Olabe J A and Aymonino P J, J Inorg Nucl Chem., 1980, 42(4), 581-585; DOI:10.1016/0022-1902(80)80089-3

54. Pesez M and Bartos J, Colorimetric and fluorimetric analysis of organic compounds and drugs Marcel Dekker Inc., New York; 1974, 628-630. 